\title{
Os think tanks brasileiros e a agenda de política externa de Lula da Silva e Rousseff para a África
}

\author{
Brazilian think tanks and the foreign policy \\ agenda of Lula da Silva and Rousseff to Africa
}

DOI: $10.21530 /$ ci.v15n1.2020.964

Camille Amorim ${ }^{1}$

André Luiz Reis da Silva²

\section{Resumo}

A fundamentação teórica sobre os think tanks segue arraigada à experiência pioneira estadunidense como tipo ideal, embora estudos de caso, vide Reino Unido, França e mesmo Brasil, mostrem situações distintas. Este trabalho propõe, considerando o objetivo de tais instituições de influenciar e modelar ação de atores políticos com base em sua expertise, adentrar na produção ideacional contemporânea dos think tanks brasileiros sobre as relações Brasil-África durante os governos Lula da Silva e Rousseff ${ }^{3}$. Uma revisão teórica sobre os think tanks é seguida da apresentação do conteúdo das produções de CEBRI, BPC, Igarapé e IPEA acerca da agenda brasileira para África. A pesquisa está centrada em produção escrita, artigos, relatórios mais detalhados sobre o continente, considerando como ponto de convergência entre as produções os tópicos de cooperação sul-sul e oportunidade de internacionalização para as empresas brasileiras. Apesar da importância da África para o período analisado, o tema aparece restrito a poucos think tanks, que apontam para continuidade discursiva entre as gestões de ambos os governos, sendo, este último, responsável pelo redirecionamento estratégico, prevalecendo as relações empresariais a despeito da cooperação sul-sul.

Palavras-chave: Análise de Política Externa; Relações Brasil-África; Think Tanks.

1 Doutoranda pelo PPG em Estudos Estratégicos Internacionais/UFRGS. Mestre em Estudos Estratégicos Internacionais e especialista em Estratégia e Relações Internacionais Contemporâneas pela UFRGS. ORCID: https://orcid.org/0000-0001-5918-835X; email: camille.amorim@gmail.com

2 Doutor em Ciência Política. Pós-doutorado na School of Oriental and African Studies/University of London. Professor dos PPGs em Estudos Estratégicos Internacionais e Ciência Política da UFRGS/Brasil. Bolsista de Produtividade em Pesquisa do CNPq (PQ2). ORCID: https://orcid.org/0000-0003-2593-1189; email: reisdasilva@hotmail.com

3 Essa pesquisa foi financiada pela Coordenação de Aperfeiçoamento de Pessoal de Nível Superior - Brasil (CAPES) e pelo Conselho Nacional de Desenvolvimento Científico e Tecnológico (CNPq).

Artigo submetido em 14/06/2019 e aprovado em 06/03/2020. 


\section{Abstract}

The academic literature of think tanks has been related to the United States experience as an ideal type, despite case studies about the United Kingdom, France or even Brazil show distinct but feasible accommodations. This paper aims to discuss the ideational production of Brazilian think tanks about Brazil-Africa relations during the governments of Lula da Silva and Rousseff, considering the main purpose of these institutions on influencing and modelling the action of political actors based on intellectual expertise. A theory review is followed by an exposition of intellectual production of CEBRI, BPC, Igarapé and IPEA about the foreign policy agenda for the continent, considering two topics of convergence: southsouth cooperation and internationalization of Brazilian companies. Despite the importance of Africa for the foreign policy agenda during these governments, the field of research still restricted to very few think tanks. The studies point out the discursive continuity between both presidencies, being the last one responsible for a strategic adjustment, prevailing companies' internationalization emphasis over the south-south cooperation.

Keywords: Foreign Policy Analysis; Brazil-Africa Relations; Think Tanks.

\section{Introdução}

Os think tanks ainda carecem de maior atenção dentro da academia, uma vez que a fundamentação teórica segue vinculada à experiência estadunidense como um tipo ideal, embora estudos de caso de países distintos mostrem outras acomodações. Este trabalho tem como objetivo, através de uma análise qualitativa de conteúdo, adentrar na produção ideacional dos think tanks brasileiros sobre as relações Brasil-África durante as gestões Lula da Silva e Rousseff (2003-2016). É pressuposto para isso o propósito dessas instituições em influenciar e modelar a ação de atores políticos e a própria política pública com base em sua expertise. Igualmente, parte-se do entendimento, difundido na academia, que no referido período ocorreu um aprofundamento sem precedentes no eixo de relacionamento entre o país e o continente africano (Oliveira 2015). Dessa forma, esse trabalho busca, além de contribuir para a literatura de análise de política externa brasileira refletindo acerca do papel dos think tanks para o processo decisório, promover maior discussão acerca dos interesses brasileiros nas relações com o continente no século XXI a partir da perspectiva dessas instituições.

De forma a operacionalizar o estudo, percorreu-se um processo metodológico que não busca esgotar as possibilidades de think tanks e de conteúdo disponíveis 
para análise. Na verdade, é proposta interpretação qualitativa plausível, a partir da análise codificada e triangulação entre relatórios e literatura (Gibbs 2009). A amostragem de think tanks foi selecionada a partir da listagem das Américas Central e do Sul, de acordo com o Global Go To Think Tank Index Report de 2017 (McGann, 2018), publicado pela Universidade da Pensilvânia, edição essa que abarcou as produções do recorte temporal dos governos estudados. O ranking não compreende uma série de think tanks brasileiros conhecido do público especializado em política externa, contudo, foi uma ferramenta pragmática para não incorrer em preferências ou possíveis parcialidades. O ranking, cabe mencionar, é a principal listagem internacional de instituições dessa natureza. Essa preocupação em encontrar uma referência científica e internacionalizada ${ }^{4}$ para coletar a amostragem se faz pertinente diante da dificuldade em conceituar tais instituições, visto que elas tomam as formas mais diversas, conforme o sistema político e cultura de cada país (Denham e Garnett 2004).

A análise proposta neste artigo se restringe às publicações escritas em formato de policy briefing, relatórios de pesquisa ou artigos de think tanks que apresentaram grupos de trabalho especializados na temática África, institucionalizados ou ad hoc. Cabe, contudo, enfatizar que esses think tanks possuem vasta gama de estratégias para divulgar suas ideias que ultrapassam o formato escrito. Porém, optou-se pela delimitação, uma vez que é esse tipo de material que reúne mais informação, ou as principais, e que transita diretamente entre interessados na agenda e o núcleo decisório, além de pautar também outras ações dessas mesmas instituições. Dito isso, observou-se que onze, dentre quatorze listados no ranking, abordavam assuntos relativos à política internacional. Contudo, a política externa brasileira para África apareceu explicitamente em conteúdo escrito apenas em quatro, a saber: BRICS Policy Center (BPC), Centro Brasileiro de Relações Internacionais (CEBRI), Instituto de Pesquisa Econômica Aplicada (IPEA) e Instituto Igarapé.

Como ficará claro mais adiante, foi notável entre as publicações a convergência de agenda dos think tanks no que se refere à cooperação sul-sul para o desenvolvimento e às potencialidades mercadológicas para o empresariado

4 É necessário, ademais, elucidar como ocorre o desenho dos rankings anualmente publicados. Em geral, há uma combinação de nomeações oriundas de personalidades e especialistas ligados às agendas e às mais diversas regiões geográficas. Cerca de 7500 think tanks e 8500 jornalistas, doadores públicos, privados e policy-makers de todo o mundo participam desses processos, que incluem, ainda, uma revisão das nomeações e classificações por pares e especialistas. Diante das tantas faces de um think tank, o ranking é um mecanismo satisfatório, embora não seja perfeito, visto que fornece caminhos transparentes para o mapeamento de tais instituições, a despeito de quaisquer elementos subjetivos e contraditórios naturais aos think tanks. 
brasileiro. Essa divisão norteou a análise, antecedida por uma primeira unidade de revisão teórica, com o intuito de entender como as ideias podem influenciar a formulação de políticas públicas e como outros estudos de caso podem fornecer elementos para discutir a conformação dos think tanks brasileiros, o que é feito em sequência. Posteriormente, o conteúdo das produções dos think tanks acerca da política externa brasileira para África é tratado especificadamente (são detalhados os tópicos de cooperação sul-sul e o continente africano como oportunidade de internacionalização para as empresas). Por fim, há considerações finais sobre os think tanks e agenda para África.

\section{O debate sobre os think tanks: uma revisão da literatura}

O conceito de “comunidades epistêmicas”, reconstruído por Haas (1992), pode ser de grande utilidade para se pensar os think tanks. Haas (1992) utiliza o conceito para estudar o controle sobre o conhecimento e a informação e como estes são usados como dimensão de poder. Nesse sentido, o conceito de comunidade epistêmica é tido como mais que uma comunidade científica conectada pela preocupação com a ciência no sentido natural, mas sim como rede pautada em expertise, na qual níveis políticos são alcançados por meio do reconhecimento de tamanha capacidade. Ademais, definem-se como profissionais de distintas origens e multidisciplinares, que compartilham um conjunto de crenças e princípios e que fornecem uma lógica baseada em valores para ação social dos membros (Haas 1992).

Essas características se tornam visíveis pela observação da história dos think tanks. O surgimento desses organismos remonta ao início do século XX, nos Estados Unidos, sob uma base social de estima à importância das ideias que embasavam e influenciavam atores políticos. Fortaleceram-se ao prover serviços diversificados, a exemplo da RAND Corporation, que presta serviços tanto de engenharia naval, quanto análises políticas com recursos humanos altamente especializados. Assim como a atividade acadêmica, o produto final do trabalho de um think tank é o conhecimento, a produção intelectual e o grau de especialidade, que oferece legitimidade para atuação da organização. Porém, há uma divergência entre os dois organismos: enquanto a universidade obedece à missão principal do avanço de conhecimento, os think thanks se preocupam mais com a ação política (Abelson 2006). 
Ao inserir tais organizações sob aparato da disciplina de análise de política externa, Abelson (2006) ressalta que é impossível seguir restringindo o processo decisório à esfera estritamente pública e que observar a atividade dessas instituições é construir uma ponte entre a opinião pública e os decisores, ambos focos diretos dessas produções ideacionais. Sob esse viés, os think tanks podem ser pensados como atores que auxiliam os líderes, fornecendo suporte para que levem em conta com precisão os custos e benefícios das ações a serem tomadas, reduzindo a margem para incertezas e desenvolvendo um ambiente de tomada de decisão estável. Sob outra perspectiva, os think tanks são também responsáveis por, principalmente durante os estágios iniciais da política pública, ajudar a forjar parâmetros para o debate na sociedade (Abelson 2006). Ademais, não é possível esperar que todos think tanks participem igualmente durante os estágios da política, por um princípio básico de não compartilharem interesses e metas iguais, ou mesmo porque, embora sejam especialistas, não possuem as mesmas aptidões. Por essas características, generalizações são problemáticas no estudo dessas instituições.

A literatura existente não avança no sentido de mitigar ou simplesmente explicar as ambiguidades decorrentes da impossibilidade de generalizações sobre o papel exercido pelos think tanks. Há de se reconhecer tamanha abstração, se comparado ao lobby, como algo inerente ao produto específico dessas organizações: ideias dificilmente são quantificáveis, sendo impossível mapear, com precisão, o momento de concepção e o caminho levado até sua vocalização. No caso brasileiro, tais instituições ainda são um fenômeno recente e em vias de amadurecimento. Contudo, atentar para a importância dos think tanks junto ao processo decisório pode oferecer um caminho alternativo para pensar as relações entre Estado e atores interessados em política externa, no caso específico da agenda para África. É um exercício para identificar a conexão entre ideias, atores, e política externa em um contexto em que as pesquisas acadêmicas ainda esbarram nas limitações da diplomacia pública do Itamaraty.

\section{Da literatura internacional sobre think tanks ao caso brasileiro}

Entender o caso estadunidense é uma preocupação de muitos autores (Smith 1991; Abelson 2006; Desmulins 2000; Parmar 2004). Há convergência de abordagens no sentido de atribuírem aos Estados Unidos uma posição próxima 
à de tipo "ideal Weberiano", norteador para análise de outras experiências no mundo. Assume-se, aqui, parcialmente essa afirmação, já que os Estados Unidos são, de fato, a experiência pioneira e, consequentemente, melhor mapeada pela literatura. Entretanto, é impossível dimensionar em termos de o que seria uma experiência perfeita, exemplos disso são os casos britânico, francês e brasileiro. A depender de cada sistema político os think tanks se acomodam em formatos diferenciados, apesar da existência dessas instituições ser uma tendência global.

Sobre ultrapassar o caso americano, é possível de início lembrar que a combinação entre conselheiros políticos e líderes é uma prática antiga. É o objetivo de um dos livros mais conhecidos do ocidente: O Príncipe, de Maquiavel. Smith (1991), a exemplo dessa prática, cita o relacionamento de Aristóteles e Alexandre, de Sêneca e Nero, de Hobbes e o Príncipe de Gales, e, mais recentemente, de Tugwell e Franklin Roosevelt ou de Walter Heller e Kennedy. O hábito de recorrer a especialistas privados e sem perfil burocrático define um relacionamento responsável por expor nitidamente a incapacidade de governar alheio à produção intelectual extra-estatal (Smith 1991), demanda favorecedora do florescimento dos think tanks.

Desde a origem estadunidense no início do século XX, os think tanks foram delineados como institutos de pesquisa política sustentados pela filantropia (Abelson 2006; Smith 1991). Sua nomenclatura própria de "tanques de conhecimento" veio na sequência, após serem reconhecidos pelo serviço prestado durante a Segunda Guerra. Suas bases se solidificaram entre 1946 e 1970, conforme passaram a se beneficiar de contratos com o governo, prevendo produção de conhecimento técnico nas áreas mais diversas (desde as ciências sociais até engenharia), necessidade dos Estados Unidos no contexto de Guerra Fria. Após 1970, os think tanks ganharam um novo perfil: abraçam ideologias, são envolvidos em ativismo político e passam a pautar suas atividades em um misto de propaganda e de pesquisa acadêmica. Para Abelson (2006) é nesse momento que institutos - vide o CFR - e especialistas em política externa ganham maior visibilidade, pela preocupação dos decisores em encontrar munição ideacional para nortear as responsabilidades hegemônicas e para alimentar a crescente burocracia de política externa, além da demanda por mobilizar a opinião pública como legitimadora da atuação internacional da Grande Potência.

5 Council on Foreign Relations, fundado no início do século. Fortalecido, segundo Abelson (2006) no período em questão. 
Ademais, alguns exemplos de outros países podem contribuir para se pensar o Brasil. O caso francês, conforme esquematizado por Desmulins (2000), se afasta do padrão americano pelos think tanks surgirem dentro de um contexto de maior competitividade. As atividades que seriam restritas às tais organizações já eram historicamente exercidas por instituições de natureza muito diversa, como o caso dos clubes políticos, gabinetes ministeriais ou mesmo a figura personalista do intelectual francês. Esse último, tradicionalmente simbólico, não precisa ter conhecimento técnico para políticas públicas, pois é percebido pela opinião pública como exemplo de conhecimento por si. Para Desmulins (2000), no país é relevante, também, uma lacuna entre esferas acadêmica e política e o padrão de financiamento majoritariamente público dessas instituições. Analogamente, de acordo com Denham e Garnett (2004), o caso britânico contou com determinantes para o surgimento e consolidação dos think tanks, diante do espaço modesto destinado às ideias e intelectuais em um sistema político elitizado e tradicionalista. Alta coesão partidária, dominância do executivo sobre o legislativo e a ausência de assembleias regionalizadas até pouco tempo atrás, concentraram o debate ideacional sobre a política do país entre poucos atores aglutinados em Londres. A consequência foi um aumento das instituições que pleiteiam a denominação de think tanks, acompanhando tendência global que atribui peso ao termo por “marketing”, mas limitadamente influentes (Denham e Garnett 2004).

Os casos francês e britânico fornecem aparato conceitual ao caso brasileiro no sentido de constatar o surgimento dos think tanks como tendência difundida em nível internacional, com sistemas políticos diversos, constrangimentos e motivações nacionais. O Brasil seria, em alguma medida, convergente ao caso francês dada a importância do financiamento público para desenvolvimento de pesquisas, ou por terem burocratas em seu corpo técnico - como é o caso do IPEA, dentre a amostragem escolhida e cujos funcionários são concursados ou contratados temporariamente pelo governo, é, inclusive, um instituto vinculado ao Ministério do Planejamento.

O caso britânico remonta ao brasileiro quanto à predominância do poder Executivo sobre o Legislativo e sobre o fato de ambos poderes estabelecerem comunicação direta, restando pouco espaço para terceiros (como intermediários), tampouco para que ideias sejam usadas como pontes. Há no Brasil um sistema presidencialista de coalizão predominante, respaldado por um presidente institucionalmente forte, com amplos poderes legislativos de agenda e para 
nomeações executivas. O presidente é o ator central, capaz de conformar maiorias no congresso, garantindo estabilidade e governabilidade ao sistema político (Figueiredo e Limongi 1999).

Adicionalmente, no presidencialismo brasileiro há todo o debate acerca do insulamento do Itamaraty, pasta do poder Executivo responsável pela política externa. Há os que entendem que o ministério se conformou historicamente alheio aos demais poderes e também afastado da sociedade, constituindo, em si, uma força autônoma, coesa, altamente educada e profissionalizada (Cheibub 1985), capaz, não apenas de implementar a política externa, mas também de formulála. Parmar (2004), sob o mesmo viés, disserta sobre os casos dos think tanks australianos, canadenses, neozelandeses e sul-africanos: a melhor acomodação de tais organismos às realidades nacionais dependeu do quão carente a burocracia estava de receber informação especializada para suportar suas tarefas. Em condição análoga, no Brasil, não houve, por parte do Itamaraty, necessidade de recorrer à diplomacia informal que os think tanks poderiam representar para complementar sua atuação. Ao contrário, através do Instituto Rio Branco constituíram recursos para autonomia e autossuficiência intelectual. Isso acabou por retardar o fortalecimento dos think tanks.

Cabe ponderar, ainda, que a partir da década de 1990 o Itamaraty foi envolto em uma série de demandas por políticas responsivas e democratizadas que tomou o Estado brasileiro de maneira mais ampla (Faria 2012; Belém Lopes 2013; Milani 2012). Assim, o Ministério encaminhou uma série de medidas para aproximação de outros atores estatais e não estatais, buscando adaptação e preservação de sua posição ideacional privilegiada, ao passo em que construía uma face de política pública para a política externa, também nominada de diplomacia pública (Milani et al., 2015). Nessa lógica adaptativa, foi atribuído progressivamente à Fundação Alexandre de Gusmão papel estratégico como um think tank, com propósito de popularizar a política internacional. Para ilustrar isso, Faria (2012, p. 341) recorda a ironia de a newsletter da FUNAG, até 2009, vir acompanhada da imagem do afresco “A Criação de Adão”, de Michelangelo, famoso pela 'mão divina' tocando a mão humana.

Limitações dos diversos sistemas políticos não impossibilitaram o surgimento dos think tanks, contudo, afetaram de forma determinante o aprofundamento e desenvolvimento ao molde do tipo ideal estadunidense. Onde o Estado não careceu de complementação ao seu know-how, os think tanks encontraram 
menor espaço. No Brasil, isso é nítido pelo caráter ainda recente dos institutos de pesquisa identificados como tal. Dentre as organizações aqui estudadas a mais antiga foi o IPEA, criada em 1964, que passou a ser reconhecida como um think tank somente no século XXI. Já o CEBRI, fundado em 1998, enquanto o Instituto Igarapé e o BPC, foram ambos criados após os anos 2000. Além desses, há o caso da Fundação Getúlio Vargas (FGV), criada em uma instituição de ensino superior e que mais recentemente - além de ser reconhecida como universidade e de realizar consultorias para o governo - foi também ranqueada pela Universidade da Pensilvânia como um dos think tanks mais influentes do mundo ${ }^{6}$. Essa recente "conversão de institutos" em think tanks expõe um ponto também abordado no caso inglês, sobre possíveis vantagens de marketing em aderir ao que seria titulação contemporânea.

Dito isso, é pertinente enquadrar os think tanks aqui estudados conforme a classificação de Weaver (1989): Universidades sem estudantes, think tanks de contrato governamental e os de advocacy. A despeito das tipologias, cabe pontuar a cautela de Abelson (2006) sobre a complexidade desse tipo de instituição. Um think tank pode trafegar entre mais de uma classificação simultaneamente, ou mudar conforme o tempo. É necessário reconhecer também que esta é uma divisão não exaustiva, excepcionalmente centrada entre balizar pesquisa versus defesa ideológica.

Os think tanks enquadrados como universidades sem estudantes são caracterizados pelo esforço mais purista de pesquisa, com staff composto por acadêmicos com compromisso profissional de produzir e disseminar conhecimento. Eles diferem, todavia, das instituições de ensino superior pelo público alvo de suas capacitações serem os formuladores de políticas públicas. Foi possível enquadrar três, dos quatro think tanks, nessa classificação: BPC, Igarapé e CEBRI, cada um com suas especificidades. Essa tendência majoritária na amostra, aliada à juventude dos institutos, remonta aos primeiros think tanks estadunidenses, que acreditavam ser a legitimidade fruto de suposta pesquisa mais rigorosa - e menos explicitamente comprometida - com vínculos ideológicos ou partidários (Abelson 2006).

O BPC, apesar de enfatizar o teor independente das suas pesquisas, é um projeto da PUC-Rio que conta com alunos e professores em seu quadro de

6 Cabe recordar que a FGV não foi inserida nesta análise devido à ausência de estudos publicados acerca das relações Brasil-África de acordo com os parâmetros aqui estabelecidos. 
pesquisadores. Este think thank possui vasta gama de parcerias com universidades de todo o mundo e dentre os modelos de publicação utilizados está o Policy Brief, que se propõe disponibilizar conteúdo para atores políticos de maneira didática. O CEBRI, por outro lado, promove amplamente publicações - desde livros, artigos, dossiês, teses, entre outros - além de realizar encontros mensais com atores políticos para debater temas de seus grupos de estudo. O Igarapé, sob o mesmo viés, também adverte sobre o compromisso com a academia, preza pela alta qualificação de seus pesquisadores e pelo formato de seus artigos. Além disso, expõe, em seu website, seus parceiros, centros de pesquisa das Universidades Federais de Santa Catarina, Cândido Mendes, de Brasília, do Chile e de Chicago.

Outra classificação possível é a de think tanks de contrato governamental (Weaver 1989). Essa classificação corresponde a instituições que, apesar de fazerem pesquisa independente, se distinguem por terem no governo sua principal fonte de financiamento e, assim sendo, por não buscarem influenciá-lo - é mais adequado pensá-los como conselheiros. Inclusive, alguns destes think thanks já são criados com a finalidade de servir ao governo, consequentemente, gozam de privilégios especiais em relação às agências do Estado (Abelson 2006). O IPEA pode ser identificado dessa forma pois sua natureza jurídica é de fundação pública e sua existência tem a finalidade de prestar apoio técnico ao governo quanto às políticas públicas.

Advocacy, a última classificação, é caracterizada pela aproximação com uma ideologia, sob propósito de influenciar debate político corrente para um partido político, movimento social ou uma causa específica. Esses think thanks valorizam o acesso à mídia como forma de legitimação perante a opinião pública. Dentre os analisados, esse foi o perfil mais ambíguo para ser identificado. Entretanto, propõe-se uma reflexão acerca do CEBRI, que possui dois pontos a serem considerados: staff e presença na mídia. O presidente de honra da instituição é o ex-Presidente Fernando Henrique Cardoso (PSDB). Dentre os conselheiros estão Celso Lafer, Rubens Ricupero, Marcos Azambuja, Sergio Amaral e Armínio Fraga, personalidades que se destacaram no cenário político brasileiro por defenderem posturas econômicas neoliberais e a verticalização das relações exteriores, tiveram participação ativa na presidência de FHC e próximos do PSDB. O quadro a seguir resume a classificação dos institutos. 
Quadro 1 - Classificação dos think tanks analisados de acordo com Weaver (1989)

\begin{tabular}{|c|c|c|c|c|}
\cline { 2 - 5 } \multicolumn{1}{c|}{} & BPC & INSTITUTO IGARAPÉ & CEBRI & IPEA \\
\hline Fundação & 2011 & 2011 & 1998 & 1964 \\
\hline \multirow{2}{*}{ Classificação } & \multicolumn{3}{c|}{ Universidade sem estudantes } \\
\cline { 3 - 4 } & \multicolumn{2}{c|}{$\begin{array}{c}\text { Think tank } \\
\text { governamental }\end{array}$} \\
\hline
\end{tabular}

Fonte: elaboração própria com base em (Weaver 1989).

\section{O Brasil na África durante as gestões PT}

A tentativa de reconfiguração da geografia mundial foi ambiciosamente definida como estratégia de política externa brasileira e, nesse contexto, para além do multilateralismo potencializado e da expansão de mercados, a Cooperação Sul-Sul tornou-se elemento fundamental (Lima 2005). Sob esse cenário, o Brasil se colocou, sobretudo, como um parceiro, exportador de políticas sociais bem-sucedidas, com um discurso permeado de forte teor de solidariedade (Munanga 2018: Milani et al. 2015). Burges (2013) defende que foi evidente na política externa brasileira, nesse período, a ambição em reformular sua posição relativa de poder no sistema mundial, tendo o Brasil atuado como um intermediador entre norte e sul. A fundamentação desse posicionamento foi pautada no engajamento do MRE em posicionar o país como liderança, enquanto enquadrava o Sul-global como área de oportunidades.

Assim, a África pode ser considerada um elemento muito particular, tanto para o pensamento doméstico sobre o engajamento global, quanto para a construção de uma coalizão política - por trás das ambições de liderança - diante da comunidade internacional. Burges (2013) também aponta a importância de considerar os esforços brasileiros para gerenciar o fluxo norte-sul, com ênfase para a formação da coalizão e engajamento em prol de novas regras de governança global, notoriamente por meio das negociações pela OMC. Por último, considerando já construído o perfil de intermediador entre os polos e isso já em atividade, o autor enxerga o Brasil como coordenador de diversos fóruns voltados para construção de vínculos com outras áreas de desenvolvimento, no qual a África surge como relacionamento estratégico (Burges 2013).

As relações entre Brasil e o continente passaram por múltiplos contextos, desde a colonização, escravidão até o estreitamento de laços políticos, sociais e 
econômicos. Costa e Silva (2003) lembra que os soberanos do Benin e de Lagos foram os primeiros a reconhecer a independência brasileira, além da movimentação que o 7 de setembro de 1822 ocasionou em Benguela para uma suposta união entre Brasil e Angola. Diante de um recorte histórico mais alargado, há quem reconheça movimentos oscilantes entre o Brasil e a África, com ênfase para o ensaio durante o período da Política Externa Independente (Munanga 2018). Mais adiante, na década de 1970, esse eixo de relacionamento foi recuperado com a erosão do conceito de comunidade luso-brasileira (Cervo 2009). Como marco do relacionamento desse período, há o reconhecimento da independência de Angola, fato realizado com notória antecipação à comunidade internacional (tal qual os soberanos africanos e a independência brasileira) e, também, os pontos de Azeredo da Silveira para a 'nova política externa brasileira': incremento da cooperação sul-sul, respeito aos princípios de soberania e autodeterminação e repulsa ao colonialismo e à discriminação racial (Cervo 2009).

O século XXI é marcado por uma reoxigenação das relações (Saraiva 2015), após o afastamento do perfil seletivo com o continente, que pautou a década de 1990 e cuja narrativa foi permeada por representações da África como um continente repleto de pobreza, conflitos e autoritarismo (Filho 2018). No novo momento, os números chamam atenção, com o aumento da quantidade de postos diplomáticos e abertura de novas embaixadas no continente, que atingiram patamares expressivos, totalizando 34 Embaixadas e 2 Consulados - os quais impulsionaram o Itamaraty a reorganizar internamente sua estrutura. Essa revisão de orientação para o continente só foi possível, também, por ter encontrado respaldo do outro lado do atlântico, por intermédio das elites africanas, que reconheceram no Brasil suporte para elevação de sua autonomia.

As elites africanas identificaram, no Brasil, um espelho que refletia a imagem que pretendiam projetar: de ex-colônia que conseguiu construir um novo contexto em termos culturais e econômicos (Saraiva 2015). Ambos os polos dessa relação vivenciaram, no início do século XXI, um renascimento em termos culturais e identitários (Munanga 2018). Assim, agendas do Sul Global relacionando apoio ao desenvolvimento, fortalecimento cultural e questionamento do protecionismo das grandes potências permearam o relacionamento. Para o Brasil o incremento significativo no comércio foi apenas um dos aspectos (Oliveira 2015), apesar de ainda encontrar em outros países emergentes, como Índia e China, concorrência difícil por conta do gigantismo de suas políticas para o continente (Visentini 2013). 
Sobre as gestões PT, predomina na literatura uma crítica, embora em tons e formatos diferenciados, contrapondo o quanto Lula e Dilma divergiram ou se aproximaram, seja em termos discursivos ou práticos. Cervo e Lessa (2014) assumem postura mais dura, alegam que a dificuldade em dialogar com a sociedade encaminhou a gestão Dilma para a inércia. Em tom mais moderado, Saraiva (2014) ressalta que fora deixada herança positiva em termos de estratégias bem definidas para condução da PEB, preservação da corrente autonomista frente ao Itamaraty e envolvimento de outras agências governamentais na política externa. Entretanto, o resultado final foi de retração de protagonismo ante cenário mundial, resultante de proatividade restrita a "movimentos espasmódicos" e sem continuidade, sem projeto de inserção estratégica a longo prazo. Cornetet (2014) se contrapõe em termos gerais à ideia de declínio e defende apenas uma contenção, tom esse identificado também em Silva (2018) ao atentar para as dificuldades impostas por uma conjuntura internacional mais difícil e uma crise interna que limitou a anterior altivez da política externa.

O trabalho de Milani, Pinheiro e Lima (2017) é um exercício para condensar todas essas percepções. Os autores entendem que alguns posicionamentos e contradições nas diretrizes de política externa durante os governos do PT podem ser melhor entendidos utilizando o argumento do dilema de graduação, ou seja, se espera que a potência graduada exerça sua função de rule-maker, tenha ambição de proeminência, uma visão geopolítica do estratégica do Sul e atue pelo aprofundamento da relação com a região. É inquestionável que, no período analisado, o Brasil foi muito ativo em fóruns internacionais, defendeu seus interesses econômicos em instâncias globais e regionais e trabalhou em favor do aprofundamento da integração da América do Sul e da cooperação sul-sul. Foi reconhecido pelos pares e angariou apoio da bancada africana em ocasiões na FAO e na OMC.

Todavia, fissuras existiram em diversos sentidos, algo comum à potência de segunda linha, principalmente diante de críticas feitas pela oposição, mídia e respaldadas por setores estratégicos. Mesmo com relativo consenso, tornou-se difícil realizar a ambição da graduação, considerando que estratégia é justamente a balança entre interesses de agentes domésticos e externos. Em outras palavras, o Brasil teria atingido um ‘teto’ de atuação diante de seus limites políticos domésticos e dificuldades de projeção internacional mais fortes que a ambição (Milani, Pinheiro e Lima 2017). No caso em questão, o fortalecimento das relações com a África, 
impulsionado no governo Lula, provocou reações diversas no Brasil, de apoio e de crítica, e gerou intenso debate sobre os interesses estratégicos brasileiros para a região.

\section{A PEB para África na visão dos think tanks: considerações iniciais}

Após a leitura dos relatórios, foram elaboradas codificações qualitativas de caráter descritivo-analítico para analisar o conteúdo disposto nos documentos. Conforme sugerido por Gibbs (2009), privilegiou-se para codificar o conteúdo a repetição de temáticas que eram retomadas ao longo das produções de diferentes think tanks, disso foram gerados dois códigos: i. cooperação sul-sul e ii. Internacionalização de empresas brasileiras. Essa estratégia metodológica é importante para encontrar ênfases nos textos que funcionem como evidências de pesquisa e sugiram interpretação textual plausível (Gibbs 2009). A combinação entre a codificação e a seguinte triangulação dos achados com a literatura sobre política externa brasileira para África foram importantes para legitimar com rigor interpretativo os dados e os resultados analíticos. Os dois códigos são abordados pelos think tanks em termos de avaliação do passado e recomendações para o futuro, elementos estes que complexificam os códigos para além de descritivos, também com peso analítico ${ }^{7}$. Abaixo segue a lista de relatórios sob escrutínio.

7 Optou-se por isolar da análise uma produção sobre aspectos técnicos das operações de paz que o Brasil participa no continente, produzida exclusivamente pelo Instituto Igarapé. Necessidade de cunho metodológico visto que não encontra respaldo entre os demais think tanks. 


\section{Quadro 2 - Lista de fontes primárias utilizadas para análise qualitativa de conteúdo ideacional}

\begin{tabular}{|c|l|c|c|c|}
\cline { 2 - 5 } \multicolumn{1}{c|}{ Relatório } & Think Thank & Autores & Ano \\
\hline 1 & $\begin{array}{l}\text { Cooperação brasileira para o desenvolvimento } \\
\text { internacional (2005-2009) }\end{array}$ & IPEA & IPEA & 2010 \\
\hline 3 & $\begin{array}{l}\text { Ponte sobre o Atlântico - Brasil e África } \\
\text { Subsaariana - Parceria para o desenvolvimento }\end{array}$ & IPEA & Carrilho et al. & 2011 \\
\hline 4 & $\begin{array}{l}\text { Cooperação brasileira para o desenvolvimento } \\
\text { internacional (2010) }\end{array}$ & IPEA & IPEA & 2013 \\
\hline 5 & $\begin{array}{l}\text { Solidarity among brothers? Brazil in Africa: trade, } \\
\text { investment and cooperation }\end{array}$ & BPC & Renzio et al. & 2013 \\
\hline 6 & Brasil-África: a ótica dos empresariados brasileiros & CEBRI & Silberfeld & 2013 \\
\hline 7 & $\begin{array}{l}\text { Brazil's south-south cooperation with Africa } \\
\text { 2003-2013: a decade of Brazilian outreach towards } \\
\text { its Atlantic neighborhood }\end{array}$ & CEBRI & Stolte & 2014 \\
\hline 8 & $\begin{array}{l}\text { Brazilian Health and Agricultural Cooperation in } \\
\text { Angola: an overview }\end{array}$ & BPC & Fonseca et al. & 2015 \\
\hline 9 & $\begin{array}{l}\text { Brazil and francophone Africa: opportunities and } \\
\text { challenges }\end{array}$ & BPC e Igarapé & Tinasti & 2016 \\
\hline 10 & $\begin{array}{l}\text { Brazilian Cooperation for International } \\
\text { Development (2011-2013) }\end{array}$ & $\begin{array}{l}\text { IPEA } \\
\text { internacional (2014-2016) }\end{array}$ & IPEA & 2017 \\
\hline 11 & \begin{tabular}{l} 
IPEA \\
\hline
\end{tabular} & & 2018 \\
\hline
\end{tabular}

Fonte: elaboração própria.

Assim como é explicitado o potencial do relacionamento delineado entre o Brasil e a África, é notável a preocupação das instituições em justificar o porquê de o país optar por tal eixo. Os autores se esforçam para expor a aproximação histórico-cultural que data do período colonizatório, tanto com o fluxo de indivíduos trazidos para o Brasil como escravos, quanto pelo mesmo eixo colôniametrópole entre Brasil e África portuguesa. Há nos textos um reconhecimento tácito da dificuldade dos brasileiros, tomadores de decisão ou opinião pública, em recordar esse compartilhamento de raízes e a entender isso como um terreno fértil para maximizar os propósitos de projeção internacional, ou mesmo considerar os benefícios financeiros para o setor privado (Tinasti 2016; Silberfeld 2013).

O governo Lula da Silva é reconhecido por unanimidade como ponto de inflexão na política externa ao explorar, consistentemente, o relacionamento com atores 
africanos e consolidar o país sob a imagem de parceiro para o desenvolvimento através da cooperação sul-sul. Aliado a isso, Lula foi capaz de mobilizar a elite brasileira, mapeando um caminho para internacionalização das empresas nacionais. Críticas são feitas a aspectos pontuais dos projetos de cooperação e a promoção comercial, contudo, não desmerecem a relevância do legado da gestão (Silberfeld 2013).

Para o CEBRI, o governo Lula, preocupado em estabilizar a presença brasileira na África, conciliou políticas domésticas para os afrodescendentes, caracterizandose como o perfil de doador emergente e fomentador de comércio. Era reconhecida a importância dessa combinação de frentes para alavancar a imagem do Brasil como player internacional. A presidenta Dilma Rousseff (2011-2016), em contrapartida, já recebe essa imagem estabilizada e, quiçá pela sua formação economista, ressalta Stolte (2014, p. 14), opta por abordagem mais direcionada para a "África como novo mercado". Isso explicaria, em alguma medida, escolhas da gestora, como o corte de orçamento da ABC (Agência Brasileira de Cooperação) e o perdão da dívida de quase 900 milhões dólares para propiciar linhas de crédito via BNDES (Stolte 2014).

Os Relatórios COBRADI (2010; 2013, 2017; 2018) são uma série do IPEA em parceria com a $\mathrm{ABC}$ e MRE, com o propósito de mapear o levantamento da cooperação brasileira para o desenvolvimento internacional. Devido à importância estratégica para a cooperação, sendo a segunda região prioritária, abaixo apenas da América Latina, a África é abordada pelos relatórios, embora não de maneira central. Além disso, a mesma instituição lançou, especificamente sobre o eixo Brasil-África, o relatório "Ponte sobre o Atlântico - Brasil e África Subsaariana: parceria sul-sul para o crescimento", no primeiro ano da gestão Rousseff (Carrilho et al. 2011). A discussão estabelecida perpassa a história nos termos aqui já abordados, a nova arquitetura mundial a partir da emergência do BRICS, cooperação e comércio. É uma pesquisa financiada pelo Banco Mundial com a proposta de mostrar como o financiador pode aprender com o modelo de relacionamento contemporâneo entre Brasil e o continente africano. Essa ideia da cooperação brasileira como modelo para organizações internacionais e países desenvolvidos retorna no Relatório COBRADI que avalia o período de 2014 a 2016, no qual o IPEA ressalta que os 9 anos de pesquisa ininterruptas que resultaram em tais informes tornaram o think tank referência em estudos de cooperação para o Banco Mundial, FMI e OCDE (IPEA 2018). 
É possível entender o objetivo do relatório Ponte sobre o Atlântico de duas formas não excludentes: primeiramente, o think tank governamental presta serviço de mapear como a cooperação sul-sul proporcionou aos africanos maior margem de barganha para recusar os termos de relacionamento menos vantajosos e neocoloniais, em que o Banco Mundial é representante (Nkrumah 1967). A produção evidencia o papel dos emergentes no cenário internacional e o quanto os agentes tradicionais precisam rever suas políticas na África. Uma segunda avaliação também expõe que, por recomendar ao Banco Mundial maior ênfase em prover informações sobre mercados emergentes e intensificação da avaliação de projetos sul-sul em andamento, deixa implícita a impressão de que o governo brasileiro estaria, em termos muito sutis, assumindo a incapacidade de seguir como financiador da relação com o continente, seja pela alteração de interesses por parte dos formuladores, seja por questão conjuntural.

Os relatórios seguintes são de 2013, marcando o início de uma série de pesquisas a respeito das relações Brasil-África. O BPC foi o maior publicador sobre essa temática (2013a) (2013b) (2015) (2016), além de, em 2016, desenvolver um relatório em parceria com o Instituto Igarapé. A produção do BPC aconteceu por meio do Projeto "Brazilian South-South Cooperation and the BRICS: Changing Strategies in Africa” (Brazil - SSC), com financiamento principalmente do DFID - Department for International Development do Reino Unido. Esse interesse de atores como o Banco Mundial e o Reino Unido em financiar pesquisas brasileiras pode apontar que atores tradicionais notam o sucesso da experiência dos emergentes e a necessidade de aprender com eles para moldar e atualizar suas práticas.

O CEBRI, por outro lado, subdivide suas pesquisas entre regiões, no caso em questão “África e Oriente Médio”. As pesquisas de 2013 e 2014 foram financiadas por atores relevantes das relações Brasil-África: BNDES, Caixa, Banco do Brasil e Odebrecht. Além deles, a Veirano Advogados (escritório brasileiro membro de redes internacionais de prestadores de serviço, segmento este que contempla o maior número de empresas atuando internacionalmente) e que também foi responsável pelo financiamento de projetos (Milani et al. 2015 71). Pela identificação dos financiadores, é possível aferir que os artigos do CEBRI são bom recurso para entender qual o suporte ideacional está presente entre os decisores brasileiros, afinal, há uma combinação de apoiadores tanto privado quanto públicos 


\section{A cooperação Sul-Sul: da exportação de modelos nacionais à pavimentação para internacionalização empresarial}

A cooperação é parte importante de um plano maior para o Brasil como player internacional de peso. Está atrelada à estratégia de exportar modelos nacionais de políticas sociais, diante da demanda de parceiros internacionais (IPEA 2018). Todavia, um decréscimo significativo na execução orçamentária dos projetos na África via ABC a partir de 2011 foi frequentemente mencionado pelo CEBRI, BPC e Igarapé como algo preocupante para a sustentabilidade desse processo, bem como para garantir a total execução e qualidade dos projetos. Essa redução financeira se insere no corte de gastos mais amplo do Governo com a cooperação, conforme aponta o IPEA (2018) no último Relatório COBRADI. Embora sem realizar avaliação crítica dessa questão, é apontado que o montante destinado em 2010 era de $\$ 2.428 .489 .947,00$ e em 2015 estava em $\mathrm{R} \$ 389.488 .759,00$. Em 2016 os valores subiram vertiginosamente para além de R $\$ 3.177 .090 .270,00$, com a única justificativa de arcar com os compromissos atrasados com organismos internacionais de mais de três bilhões de reais em dívidas que ameaçavam a participação e o poder de voto do Brasil nessas instituições.

Além de apontar que os principais parceiros brasileiros para cooperação estão na África lusófona, em particular Angola e Moçambique, autores do CEBRI, Igarapé e BPC identificam dificuldade de transbordamento dessas fronteiras. O primeiro afirma que os projetos em Botswana, Sudão, Burkina Faso, Benin, Gâmbia, Guiné Equatorial, Tanzânia e Zâmbia não ultrapassaram os países da Comunidade de Países de Língua Portuguesa em termos de valores financeiros destinados à cooperação, mas tiveram sucesso significativo para os fundos limitados (Stolte 2014). Já Igarapé e BPC complementam que a África Francófona pode representar, para o Brasil, dedicação a projetos de infraestrutura e fortalecimento de instituições que possam formar bases para a atuação empresarial a longo prazo (Tinasti 2016).

São ressaltadas as atuações da EMBRAPA, SENAI e Fiocruz, como agentes institucionais promotores de cooperação, em parceria com a ABC. Contudo, há diferentes ênfases em suas atividades. O IPEA reitera a capacidade dessas instituições em reproduzir positivamente experiências domésticas de sucesso, por exemplo, como o agronegócio, ensino profissionalizante, medicina tropical, tratamento de HIV, Malária e anemia falciforme, além da proteção social e energia sustentável. Para o mencionado think tank governamental, o caráter ainda recente 
dos projetos, uma vez que todos foram iniciados a menos de dez anos, seria impedimento para avaliação adequada (Carrilho et al., 2011), anulando potenciais críticas vistas em maior escala nos demais. Nos Relatórios COBRADI (2010; 2013; 2017; 2018) o IPEA reitera a ideia de exportação da experiência nacional: a expertise no plano nacional seria a grande base da participação de instituições burocráticas extra-MRE na agenda africana, enviando técnicos para o continente, com diversas atribuições. Contudo, mesmo oito anos após a divulgação do relatório de Carrilho et al. (2011), o IPEA seguiu se isentando de avaliações críticas e recomendações para o futuro, colocando, por exemplo, o objetivo dos relatórios aqui citados simplesmente como promoção da transparência e da sistematização de informações necessárias para a formulação de políticas públicas.

Em contrapartida ao IPEA, o BPC, cuja pesquisa se desenvolveu por meio de entrevistas com atores políticos africanos, define em termos de baixo desempenho a cooperação Brasil-África e os projetos como subexecutados, pela dificuldade de relacionamento com entidades locais, baixo poder de decisão dos órgãos executores e altas taxas de rotatividade de profissionais. Há críticas pontuais ao Projeto de Fortalecimento do Sistema de Saúde de Angola (PROFORSA), dentro da preocupação com medidas top down vindas do Brasil, vide a exigência em estabelecer regras de gestão de saúde inviáveis para a realidade local, ou, por exemplo, a recusa brasileira em aceitar mães portadoras de HIV para amamentar seus filhos, enquanto Angola reitera que esse é o único alimento para muitas crianças que passam fome (Fonseca, Zocal e Esteves 2015).

Para o BPC, existe importante limitação para os agentes brasileiros executarem funções básicas, como o caso do pagamento dos trabalhadores do projeto da construção do laboratório farmacêutico em Moçambique, em que indivíduos são remunerados pelo pagamento de diárias, devido a limitações burocráticas no Brasil. O think tank deixa duas recomendações claras: é necessário aprovar um marco regulatório abrangente para a cooperação, assegurador da desburocratização de processos de compras e aquisições de bens e serviços e também para contratação de recursos humanos e transações financeiras, o que motivaria aceleração de resultados junto às populações locais. Além disso, há de se considerar que o governo ainda carece de maior levantamento e sistematização de dados, para isso se reflete sobre maior inserção do IPEA, sugere o BPC (Renzio et al., 2013a).

É claro o enquadramento da cooperação sul-sul nos relatórios como tema necessário a ser abordado, já que é interpretado como mecanismo garantidor de elementos chave para a subsequente instalação do setor privado brasileiro. 
É por meio da cooperação Sul-Sul que se pode fornecer infraestrutura adequada, recursos energéticos e mesmo profissionais devidamente capacitados para que empresas se sintam mais propensas a encarar o desafio de se internacionalizar via continente africano. Dentro desse contexto, a cooperação entre países africanos e outras potências emergentes também são importantes para a iniciativa privada brasileira, apesar de os relatórios não abordarem possíveis temáticas como complementaridade ou competitividade entre os emergentes, ou papel da liderança entre atores como Índia e China além do Brasil, temáticas estas que poderiam trazer um debate mais denso e mais segurança ao setor privado.

\section{O olhar pragmático: a África estratégica para o empresariado}

As empresas brasileiras presentes na África são majoritariamente do setor da construção civil, além dos setores de mineração e petróleo. Odebrecht e Petrobrás são os atores de maior destaque, por possuírem operações vultosas no continente desde a década de 1980. Dentre as demais estão Vale, Camargo Corrêa, Engevix, Queiroz Galvão, Asperbras, Fidens e Stefanini (Renzio et al. 2013: Silberfeld 2013; Stolte 2014). Estas, por sua vez, expandiram suas atividades a partir da gestão Lula da Silva, período em que imperou o entendimento do governo que promover o setor privado é também promoção do soft power brasileiro. Tal engajamento do governo é avaliado positivamente por todos os think tanks. Nesse sentido, de acordo com o CEBRI, a mudança de perfil entre Lula e Rousseff não representou grandes transformações para as empresas brasileiras. As iniciativas como perdão de débitos de países africanos em quase US\$ 900 milhões de dólares em 2013 (devido às exigências do BNDES para financiamento,) e também a facilitação de mecanismos de crédito, a criação do departamento África no BNDES e do escritório do mesmo em Johanesburgo atestam a continuidade entre ambos os presidentes (Stolte 2014).

IPEA e CEBRI interpretam positivamente uma série de medidas de Lula da Silva e Rousseff em favor da internacionalização de empresas via continente, como a promoção de missões comerciais, reestruturação da APEX, financiamento por meio do BNDES, instalação de sucursais dos principais bancos estatais - Caixa Econômica e Banco do Brasil - além do Bradesco, banco privado. Isso, associado ao escopo de projetos de cooperação sul-sul, forneceu aparato para convencimento do empresariado quanto às benesses da empreitada (Silberfeld 2013; Carrilho et al. 
2011). Sob a ótica dos empresários, o relatório do CEBRI ressalta que tal conjunto de iniciativas, aliado à promoção de seminários e capacitações, foi elemento propulsor de mudança de paradigmas entre setores estratégicos, entidades como a Federação das Indústrias do Estado de São Paulo, que entendiam como custosas, ou não demonstravam conhecimento acerca das oportunidades no continente (Silberfeld 2013).

Há um entendimento comum entre o CEBRI, BPC e Igarapé sobre existir oportunidades ainda não esgotadas pelo empresariado na África, muito pela concentração de incentivos do governo brasileiro em países da CPLP e pela ênfase nas campeãs nacionais (Silberfeld 2013; Renzio et al. 2013b). Mesmo nesses locais, o setor de comércio de bens e serviços não é explorado a contento e sequer visitas exploratórias são feitas. Isso é reflexo, criticam os três think tanks, de ênfase exagerada nos setores de mineração, construção e petróleo, nos quais o Brasil insiste, mas não consegue estar à frente de outros emergentes como a China (Tinasti 2016). Essa lacuna quanto aos bens e serviços poderia ser preenchida por pequenas e médias empresas, para ultrapassar uma mera "experiência de gigantes nacionais" (Silberfeld 2013; Renzio et al. 2013b).

A resposta do governo pode ser vista no relatório do IPEA (2011), o qual sugere que o Banco Mundial auxilie a entrada de empresas de médio e menor porte por meio da promoção de conhecimento. Como incentivo a essa ampliação, CEBRI e BPC recomendam que o governo se preocupe mais com a transparência de gastos, algo atrativo ao setor privado. Ademais, seria importante o incremento do diálogo com atores das mais diversas naturezas, como forma de atrair legitimidade (Renzio et al 2013a) e com os empresários, os quais, por sua vez, devem prestar melhores justificativas para o eixo governo e sociedade civil local acerca de comportamentos, a exemplo dos fluxos forçados para projeto de mineração da Vale em Moçambique ou a diferença entre salários de brasileiros e africanos de cargos iguais, algo muito comum (Renzio et al 2013b). Os relatórios se mostram limitados no sentido de comparar ação do Brasil em relação aos demais emergentes no continente.

\section{Considerações finais}

Os think tanks brasileiros de política externa aqui avaliados são um fenômeno recente se comparado ao caso mais avançado dos Estados Unidos. A classificação de Weaver (1989) como “universidades sem estudantes” é amplamente adequada 
para os institutos selecionados, tendência que remonta à preocupação dos primeiros think tanks estadunidenses em serem associados muito mais à academia do que aos possíveis vínculos ideológicos ou partidários, como estratégia para atrair credibilidade (ABELSON, 2006). É importante atentar para essas organizações pelas redes em que estão envolvidas, pela proximidade com atores sociais interessados em influenciar o processo decisório pelas ideias. Além disso, há também a tese acerca de sua atuação como ponte entre a opinião pública e o círculo decisório. Esse trabalho propôs, portanto, motivar o debate sobre a relação entre think tanks e a política externa.

Os think tanks atuam de maneira semelhante em suas pesquisas, reconhecem méritos e criticam aspectos pontuais para apontar recomendações. As críticas não anulam a avaliação positiva da gestão Lula da Silva em termos gerais haja vista os esforços pela cooperação sul-sul e em fomentar a ida do empresariado para o continente. Isso é visto, por mais que o CEBRI, especificamente, seja enquadrado em uma tipologia de advocacy de um partido distante do PT. O mesmo se entende quanto ao governo Dilma, embora ajustes sejam apontados pelo equilíbrio entre continuidade discursiva e ênfase na atuação do empresariado. Em outras palavras, tais estudos destrincham a natureza da discussão acadêmica já existente acerca de rupturas e continuidades entre ambas gestões no caso da política brasileira para África ao identificar rupturas no que se refere à cooperação, a despeito de continuidades da pauta de internacionalização.

É possível pensar como a produção dos think tanks brasileiros reflete um momento marcado pela convergência de interesses domésticos como elemento facilitador da política externa para África. Tendo em conta que o olhar para o continente pode adquirir múltiplas facetas, seja em sentido mais romântico ligado ao compartilhamento de uma identidade negra, ou olhar mais pragmático quanto à identificação de oportunidades vantajosas para os objetivos do Estado em maximizar sua projeção internacional e da iniciativa privada em lucrar, é possível dizer que o olhar para África se reflete nos escritos aqui estudados de forma pragmática, sem que o recurso ao argumento identitário seja totalmente invisibilizado, mas assumindo aspecto secundário.

Essa pesquisa não objetivou esgotar as possibilidades sobre o caso brasileiro. Existem mais elementos teóricos e empíricos para seguir mapeando o fenômeno dos think tanks no país. Exemplo disso está no reconhecimento de Abelson (2006) quanto à importância de atualização das classificações de Weaver (1989), com a adição das categorias candidate-based e think tanks de legado. O propósito da 
primeira é tanto contornar legislações de campanha nos Estados Unidos quanto propor mais um canal de comunicação entre candidato e eleitor - é possível refletir se essa tendência alcança também o Brasil. O segundo tipo corresponde a institutos de pesquisa criados por políticos que pretendem deixar sua marca pública após o mandato. O Instituto Lula, Instituto FHC e outras fundações partidárias podem ser terreno fértil para o aprofundamento desse estudo.

\section{Referências}

Abelson, Donald. 2006. A capitol idea: think tanks and US foreign policy. Toronto: McGill-Queen's University Press.

Belém Lopes, Dawisson. 2013. Política externa e democracia no Brasil: ensaio de interpretac , ão histórica. 1. ed.: Editora UNESP.

Burges, Sean. 2013. "Brazil as a bridge between old and new powers?" International Affairs 89: 3 (2013) 577-594.

Carrilho, Simone, Eduarda Passarelli Hamann, Keith Martin, José Flavio Sombra Saraiva, Creomar Lima de Carvalho de Souza, Fames Augusto Tibúrcio, Tijan M. Sallah e Marcos Antonio Macedo Cintra. 2011. Ponte sobre o Atlântico - Brasil e África Subsaariana - Parceria para o desenvolvimento. Washington DC e Brasília: Banco Mundial e IPEA.

Cervo, Amado Luiz. 2009. "Meios e Resultados do Pragmatismo em Política Externa (1967-1979)". In: Amado Luis Cervo e Clodoaldo Bueno. História da política exterior do Brasil. Brasília: UnB, p. 397-425.

Cervo, Amado Luiz e Antônio Carlos Lessa. 2014. "O declínio: inserção internacional do Brasil (2011-2014)”. Rev. bras. polít. int., Brasília, v. 57, n. 2, p. 133-151. Disponível em: < http://www.scielo.br/scielo.php?script = sci_arttext\&pid = S003473292014000 200133\&lng $=$ en\&nrm $=$ iso $>$. Acesso em Out. 2018.

Cheibub, Zairo. 1985. "Diplomacia e Construção Institucional: o Itamaraty em perspectiva histórica”. Revista Dados, vol. 28, no. 1.

Cornetet, João Marcelo Conte. 2014. "A política externa de Dilma Rousseff: contenção na continuidade”. Conjuntura Austral. v. 5, n. 24, p. 111-150. Disponível em: <http://www.seer.ufrgs.br/ ConjunturaAustral/article/viewFile/47628/30012 > . Acesso em: out. 2017.

Costa e Silva, Alberto da. 2003. Um rio chamado Atlântico: a África no Brasil e o Brasil na África. Editora Nova Fronteira. 
Denham, Andrew e Mark Garnett. 2004. “A 'hollowed-out' tradition? British think tanks in the twenty-first century”. In: Daiane Stone e Andrew Denham (eds.). Think tank traditions: policy research and the politics of ideas. Manchester: Manchester University Press.

Desmulins, Lucile. 2000. "French public policy research institutes and their political impact as another illustration of the French exception”. In: James McGann \& Kent Weaver. Think tanks and civil societies: catalysts for ideas and action. New Brunswick: Transaction Publishers.

Faria, Carlos Aurélio Pimenta. 2012. “O Itamaraty e a política externa brasileira: do insulamento à busca de coordenação dos atores governamentais e de cooperação com os agentes societários”. Contexto int., Rio de Janeiro, v. 34, n. 1, p. 311-355.

Figueiredo, Argelina e Fernando Limongi. 2001. Executivo e Legislativo na nova ordem constitucional. Cap. 01. 2. ed. São Paulo: FGV/FAPESP.

Filho, J. J. G. da Costa. 2018. "Ideological Repertoires of the Brazilian Foreign Policy toward Africa across three presidential administrations (1995-2016): from realism to south-south solidarity, and back”. In: Cadernos de Política Exterior. Instituto de Pesquisa de Relações Internacionais - V. 4 n. 7. Brasília. FUNAG.

Fonseca, J.E.M., G. Zocal e P.L.M.L Esteves. 2015. Brazilian Health and Agricultural Cooperation in Angola: An overview. Rio de Janeiro, RJ: BRICS Policy Center. Disponível em: < http://bricspolicycenter.org/homolog/uploads/trabalhos/6838/ doc/968418951.pdf > . Acesso em: jun, 2018.

Gibbs, Graham. 2009. Análise de dados qualitativos: coleção pesquisa qualitativa. Bookman Editora.

Haas, P. M. 1992. "Introduction: epistemic communities and international policy coordination”. International Organization. Cambridge University Press, 46 (1), pp. 1-35. doi: 10.1017/S0020818300001442.

IPEA. 2010. Cooperação Brasileira para o Desenvolvimento Internacional 20052009. Brasília: Instituto de Pesquisa Econômica Aplicada. Disponível em: < http://www.ipea.gov.br/portal/index.php?option = com_content\&view = article\& $\mathrm{id}=6874$ \& Itemid $=343>$. Acesso em: maio 2019.

IPEA. 2013. Cooperação Brasileira para o Desenvolvimento Internacional 2010. Brasília: Instituto de Pesquisa Econômica Aplicada. Disponível em: < http://www.ipea.gov. br/portal/index.php?option $=$ com_content\&view $=$ article\&id $=19070 \& I t e m i d=343>$. Acesso em: maio, 2019.

IPEA. 2016. Estatuto social - da sede, finalidade e competências. Disponível em: < http:// www.ipea.gov.br/portal/images/stories/PDFs/170613_estatuto_ipea_2016.pdf > . Acesso em: jul. 2018. 
IPEA. 2017. Brazilian Cooperation for International Development 2011-2013. Brasília: Instituto de Pesquisa Econômica Aplicada. Disponível em: < http://www.ipea.gov. br/portal/index.php?option $=$ com_content\&view $=$ article\&id $=30412 \&$ Itemid $=424>$. Acesso em: abril, 2019.

IPEA, 2018. Cooperação Brasileira para o Desenvolvimento Internacional: 2014-2016. Brasília: Instituto de Pesquisa Econômica Aplicada. Disponível em: < http://www. ipea.gov.br/portal/images/stories/PDFs/livros/livros/181219_cobradi_2014-2016. pdf $>$. Acesso em: abril, 2019.

Lima, Maria Regina Soares de. 2005. A política externa brasileira e os desafios da cooperação Sul-Sul. Revista Brasileira de Política Internacional, v. 48, n. 1, p. 24-59.

McGann, James G. 2017 global go to think tank index report. Pennsylvania: University Of Pennsylvania, 2018.

Milani, Carlos. 2012. “Atores e agendas no campo da política externa brasileira de direitos humanos”. Leticia Pinheiro e Carlos MIlani. Política externa brasileira: as práticas da política e a política das práticas. 1. ed.: FGV, 2012.

Milani, Carlos, Leticia Pinheiro e Maria Regina Soares de Lima. 2017. "Brazil’s foreign policy and the 'graduation dilema”'. International Affairs 93: 3, p. 585-605.

Milani, Carlos, E. Muñoz, R. Duarte, M. Klein. 2015.Atlas de Política Externa Brasileiro - 1a ed. - Ciudad Autónoma de Buenos Aires: CLACSO; Rio de Janeiro: EDUerj. Munanga, Kabengele. 2018. “Passado e presente nas relações África-Brasil”. In: História da África e Relações com o Brasil. Brasília: Fundação Alexandre de Gusmão (FUNAG), p. 453-488.

N’Krumah, Kwame. 1967. Neocolonialismo: último estágio do imperialismo. Rio de Janeiro: Civilização Brasileira, p. 281-306.

Oliveira, Guilherme Ziebell de. 2015. "Política Africana do Brasil: Mudança entre Lula e Dilma?”. Conjuntura Austral, Porto Alegre, v. 29, n. 6, p. 29-47, abr./mai. Disponível em: < http://seer.ufrgs.br/index.php/ConjunturaAustral/article/view/51761 > .

Parmar, Inderjeet. 2004. "Institutes of international affairs: their roles in foreign policymaking, opinion mobilization and unofficial diplomacy”. In: Daiane Stone e Andrew Denham (eds.). Think tank traditions: policy research and the politics of ideas. Manchester: Manchester University Press.

Renzio, P., G. Zoccal, J.E.M. Fonseca e A. Niv. 2013a. O Brasil e a cooperação Sul-Sul: como responder aos desafios correntes. Rio de Janeiro, RJ: BRICS Policy Center. Disponível em: < http://bricspolicycenter.org/homolog/uploads/trabalhos/5992/ doc/1619030609.pdf > . acesso em: jun. 2018.

Renzio, P., J. Seifert, G. Zoccal e M. Assunção. 2013b. Solidarity Among Brothers? Brazil in Africa: trade, investment and cooperation. Rio de Janeiro, RJ: BRICS Policy Center. 
Disponível em: < http://bricspolicycenter.org/homolog/uploads/trabalhos/6417/ doc/1779009373.pdf > . Acesso em: jun. 2018.

Saraiva, José F. S. 2015. A África no século XXI : um ensaio acadêmico. Brasília: FUNAG. Saraiva, Miriam Gomes. 2014. Balanço da política externa de Dilma Rousseff: perspectivas futuras? Relações Internacionais. n. 44, p. 25-35. Disponível em: < http://www. scielo.mec.pt/pdf/ri/n44/n44a03.pdf > . Acesso em: 25/03/2015.

Silberfeld, Jean-Claude E. 2013. Brasil-África: a ótica dos empresários brasileiros. CEBRI Artigos, v. 2, ano 8. Rio de Janeiro: CEBRI. Disponível em: < http://midias.cebri. org/arquivo/BrAfrica_OticaEmpresarios.pdf > . Acesso em: jun. 2018.

Smith, James. 1991. The Idea Brokers: Think Tanks and the Rise of the New Policy Elite. New York: Free Press.

Stolte, C. 2014. Brazil's South-South Cooperation with Africa 2003-2013: a decade of Brazilian outreach towards its Atlantic neighborhood. CEBRI. Disponível em: < http://midias.cebri.org/arquivo/ArtigoBrazilAfrica.pdf > . Acesso em: jun- 2018.

Tinasti, Khalid. 2016. Brazil and francophone Africa: Opportunities and challenges. Rio de Janeiro, RJ: BRICS Policy Center e Instituto Igarapé. Disponível em: < https:// igarape.org.br/wp-content/uploads/2016/12/1229313466.pdf > . Acesso em: jun. 2018.

Visentini, P. G. F. 2013. A África e as potências emergentes: Nova partilha ou Cooperação Sul-Sul? (A presença da China, do Brasil e da Índia). $1^{\text {a }}$. ed. Porto Alegre: Leitura XXI/CEBRAFRICA-UFRGS, v. 1.

WEAVER, R. Kent. 1989. “The Changing World of Think Tanks”. PS: Political Science and Politics, vol. 22, no. 3, pp. 563-578. JSTOR, disponível em: < www.jstor.org/ stable/419623 > . Acesso em: jul. 2018. 